\title{
Respiratory Mechanics
}

\author{
Authors: Theodore Wilson; Springer; 64 pages; \\ ISBN: 978-3-319-30508-0
}

\section{Book review}

Respiratory Mechanics by Theodore Wilson is a slim paperback volume (64 pages) describing three aspects of the way the lungs work: 1) pressurevolume relationships with regard to the lungs, 2 ) chest wall and muscles with regard to how the respiratory pump works, and 3) gas flow and transport. Relevant details about the author are missing, which I think is a loss. He is Emeritus Professor of Aerospace Engineering and Mechanics and this background and his expertise was a perfect fit for the investigation of the bioengineering aspects of lung mechanics. For me, it has been a privilege as a clinician and researcher to work with many such talented nonclinical scientists.

Although this is a slim volume, it is not for the fainthearted. The book is pitched solely with physiology in mind and the content is intense, with relevant equations used to describe what is at issue. A wider account of what is being covered is missing as are a lot of clinically relevant aspects. For an introductory and broader description, John West's treatises are more accessible. For a detailed approach, this volume is concise and lacks something in the breadth of explanation, discussion and examples.

The section on the chest wall and the respiratory pump is interestingly introduced with some comparison with the circulatory system. This whets your appetite but, for example, a comment about how the set up and relationship in fish is very different is left unanswered so one's interest is left unrewarded. The figures here about "pump handle" and "bucket handle" movement of the ribs are hard to follow and a proper anatomic demonstration would help the reader.

In the section on flow and gas transport I was disappointed to read again the suggestion that on inspiration, gas is carried to the periphery by convection in the large airways and then by diffusion in smaller airways. This confuses bulk movement of gas with the relative movement of oxygen and carbon dioxide. Diffusion has no ability to inflate an alveolus and the bulk movement of gas into the lungs is by convection. The boundary between new inhaled gas and old exhaled gas moves back into the lungs on inspiration by convection alone, and it is by diffusion that oxygen and carbon dioxide continuously move across this moving boundary following their concentration gradients.

The author touches on the observation of "gas compression" when recording forced expiration in a body plethysmograph. In the context of wave speed I had hope for a better explanation of this since the observed "compression" can only occur if wave speed is exceeded somewhere in the airways of an open system.

This book would be good for staff in laboratories undertaking complex respiratory investigations and research as they might benefit from having this volume alongside other works as a reference to understand the background to these aspects of lung function.

Where this book could be improved is that I think the author's undoubted detailed knowledge of his subject has not been best laid out in the text and figures so the transfer of this knowledge to the reader has been in some sense compromised.
Cite as: Miller MR. Book review: Respiratory Mechanics. Breathe 2016; 12: 377.

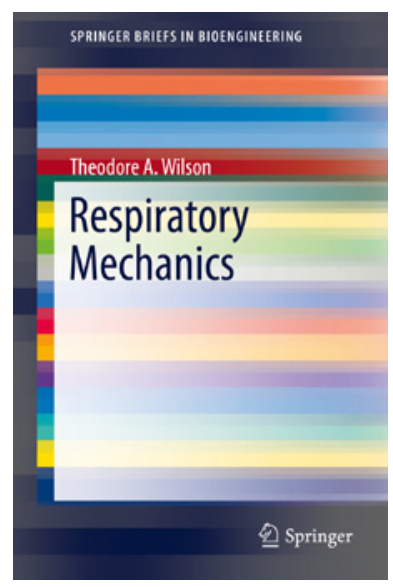

\section{Conflict of interest}

None declared. 